http://dx.doi.org/10.5007/2175-7968.2013v1n31p179

\title{
INTERPRETAÇÃO EDUCACIONAL COMO CAMPO DE PESQUISA: ESTUDO BIBLIOMÉTRICO DE PUBLICAÇÕES INTERNACIONAIS E SUAS MARCAS NO CAMPO NACIONAL
}

\author{
Neiva de Aquino Albres \\ Universidade Federal de São Carlos \\ neivaaquino@yahoo.com.br \\ Cristina Broglia Feitosa de Lacerda \\ Universidade Federal de São Carlos \\ cristinalacerda@uol.com.br
}

\begin{abstract}
Resumo: O presente trabalho analisa o desenvolvimento de pesquisa acadêmica na área de interpretação em língua de sinais, de 1990 a 2010. Adotou-se a análise bibliométrica de publicações que versassem sobre interpretação de língua de sinais e interpretação educacional. O objetivo principal desta incursão foi o levantamento e descrição de publicações de periódicos científicos internacionais e a compreensão de que forma articulam-se essas pesquisas do exterior com as pesquisas sobre interpretação educacional - IE no Brasil. Para tanto, buscamos fazer um cruzamento dos artigos internacionais com as referências bibliográficas presentes em pesquisas de mestrado e doutorado no Brasil. Constatamos que um número muito pequeno de trabalhos faz referências a esses artigos internacionais sobre IE indicando a pouca articulação e debate com a produção científica não local divulgada em periódicos.

Palavras-chave: Pesquisa. Interpretação de língua de sinais. Intérprete Educacional.
\end{abstract}




\title{
EDUCATIONAL INTERPRETING AS A FIELD RESEARCH: BIBLIOMETRIC STUDY OF INTERNATIONAL PUBLICATIONS AND THEIR BRANDS IN THE NATIONAL FIELD
}

\begin{abstract}
This study analyzes the development of academic research in the field of sign language interpretation, from 1990 to 2010. We adopted a bibliometric analysis of publications that discuss the interpretation of sign language and educational interpreting. The main purpose of this research was the survey and description of publications in international scientific journals how articulate these studies abroad with research on educational interpretation - EI in Brazil. To this end, we seek to make a crossing of international articles with references present in masters and doctoral researches in Brazil. We note that a very small number of researches make references to these articles on international EI indicating little articulation and debate with the scientific nonlocal published in journals.
\end{abstract}

Keywords: Research. Sign language interpretation. Educational interpreting.

\section{Introdução}

A Lei Federal n 10.436 de 2002 reconheceu a língua brasileira de sinais como meio legal de comunicação e expressão, sendo regulamentada pelo Decreto $\mathrm{n}^{\circ} 5.626$ de 2005 (BRASIL, 2005). Pesquisas sobre essa língua têm despontado nas últimas duas décadas (ALBRES, 2006), mais recentemente estão as pesquisas sobre a atuação de intérpretes de língua de sinais - ILS.

Constatamos que em 1985 é criado o Grupo de Trabalho de Tradução da ANPOLL - Associação Nacional de Pós-Graduação e Pesquisa em Letras e Linguística. Contudo, este grupo de trabalho não vem se ocupando das discussões sobre língua de sinais e o processo de interpretação da mesma. Esta temática tem sido tratada pelo Grupo de Trabalho Linguagem e Surdez, que dentre suas oito linhas de pesquisa destaca uma específica: Questões de tradução e interpretação.

Pereira (2010) desenvolveu um levantamento de dissertações e teses concluídas até agosto de 2009 também sobre a temática da 
interpretação em Libras. Levantou 16 dissertações de mestrado concluídas, sendo oito defendidas em programas de pós-graduação em Educação, três em programas da área da Linguística Aplicada, dois na área da Linguística, um na área da Educação Especial, uma na área da Semiologia e uma na área das Ciências da Linguagem. Por muitos anos as pesquisas sobre interpretação em língua de sinais estiveram bastante distantes dos Estudos da Tradução. A autora encontrou ainda três teses de doutorado, sendo uma na área de Letras Vernáculas, uma em Educação e outra em Educação Escolar. Assim, dentre os trabalhos de mestrado e doutorado localizados, apenas seis estão inscritos no campo disciplinar dos Estudos da Tradução.

O contexto atual da política educacional brasileira inclusiva (BRASIL, 2001; 2008), incita a necessidade imediata de um grande número de profissionais para atuar como intérprete educacional - IE. Desta forma, este campo está em expansão e é necessária a produção de conhecimento.

Esta é uma breve apresentação dos estudos sobre interpretação no cenário brasileiro que indica ser este um campo que merece ampliação. Assim, nos interessa no presente estudo identificar tendências e o crescimento do conhecimento na área de interpretação educacional nacional e internacionalmente, partindo da identificação de revistas internacionais que tenham como núcleo de estudo a educação de surdos ou estudos sobre a língua de sinais, buscando mensurar e analisar o quanto este conhecimento tem sido discutido no Brasil. Interessa também examinar o grau e padrões de colaboração entre autores internacionais nos trabalhos brasileiros; analisar aspectos dos processos de citação e co-citação; avaliar o crescimento de determinadas áreas neste campo de conhecimento e o surgimento de novos temas.

\section{Aspectos teórico-metodológicos}

A metodologia adotada no presente trabalho foi o estudo bibliométrico que consiste em um conjunto de princípios que contribuem para o estabelecimento teórico do campo de uma ciência em ques- 
tão. A função do estudo bibliométrico é a gestão do conhecimento socialmente construído. Segundo Pritchard (1969, apud. BEUREN e SOUZA, 2008, p. 3) estudos bibliométricos são "todos os estudos que tentam quantificar os processos de comunicação escrita", o que permite estabelecer perfis dos estudos de determinada área.

Para Vanti (2002) usando este método é possível identificar trabalhos, teorias e autores que estão sendo usados para o desenvolvimento do capital científico da área estudada e seu desenvolvimento cronológico, podendo identificar o crescimento ou não da área de estudo pesquisada.

Segundo Barros (1994, p. 02) "O texto é considerado hoje tanto como objeto de significação, ou seja, como um tecido organizado e estruturado, quanto como objeto de comunicação, ou melhor, objeto de uma cultura, cujo sentido depende, em suma, do contexto sócio-histórico".

Foram selecionadas revistas acadêmicas que tivessem como objetivo publicar trabalhos sobre língua de sinais, educação de surdos, interpretação em língua de sinais e que fossem disponibilizadas em bases de dados públicas (Portal de Periódicos CAPES), tendo no mínimo os resumos disponíveis.

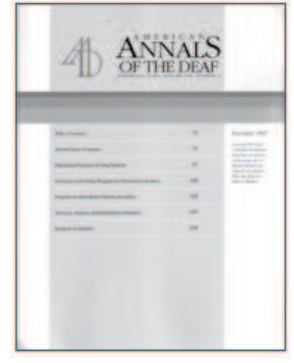

Desde 1847

American annals of the deaf http://gupress.gallaudet.edu/annals/

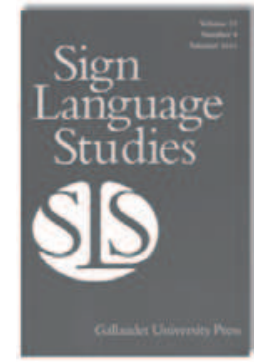

Desde 1972

Sign Language Studies

http://gupress.gallaudet.edu/SLS.html 


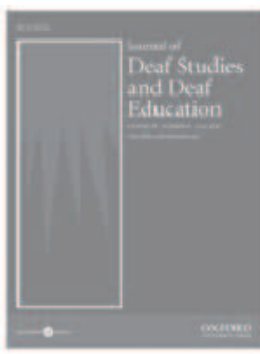

Desde 1996

Journal of Deaf Studies and

Deaf Education

http://jdsde.oxfordjournals.org/

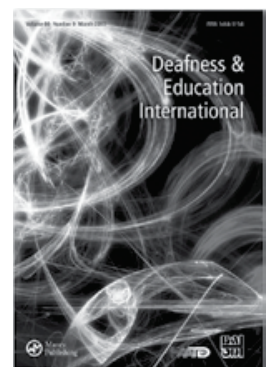

Desde 1999

Deafness \& Education

International

http://maney.co.uk/index.

php/journals/dei/

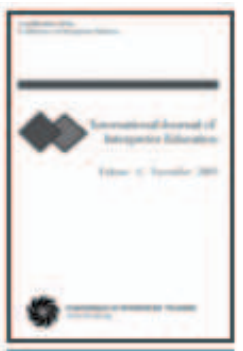

Desde 2009

International Journal of Interpreter Education (IJIE)

http://www.cit-asl.org/journal.htm

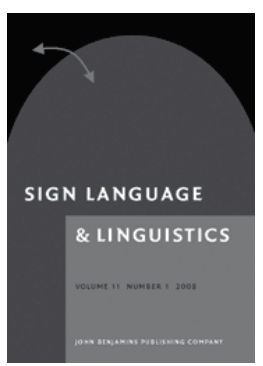

Desde 1998

Sign Language \& Linguistics http://www.benjamins.com/cgi-bin/t seriesview.cgi?series $=$ SL $\% 26 \mathrm{~L}$

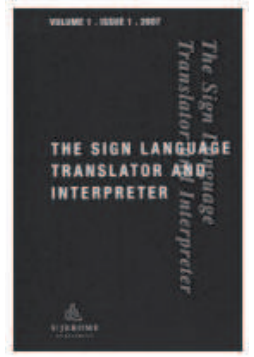

Desde 2007

Parou de ser publicado em 2010

The Sign language translator and interpreter

www.stjerome.co.uk/tsa/journal/3/ 
Nas bases de dados dos sete periódicos, o processo de seleção consistiu de duas triagens. A primeira, focada no título e palavras-chaves e a segunda focada no resumo. A primeira com as seguintes palavras: ILS ou IE (sign language interpreting e educational interpreting). A segunda seguiu o procedimento de leitura do resumo para verificação se o objeto de estudo se referia a ILS ou IE.

Após o levantamento de artigos publicados nestes periódicos, procedemos o cruzamento de citações destes mesmos artigos em pesquisas nacionais sobre IE (dissertações e teses com base em Pereira (2010)). Buscamos ainda discutir a influência dos estudos internacionais nas pesquisas nacionais com base numa perspectiva enunciativo-discursiva de Bakhtin que compreende que:

[...] pesquisador e pesquisado são sujeitos ativos prenhes de perspectivas na produção de sentidos [...] Meu encontro é com o outro na pesquisa e suas vozes repercutem sentidos diversos e visões diferentes de mundo que me lançam a sua compreensão. Nesse encontro, com o outro emerge a alteridade bahktiniana. Eu me constituo e me transformo com o outro nas interações com as palavras e os signos (SANTOS, 2010, p. 127).

Procuramos fazer a leitura dos trabalhos, na busca por apreender as relações destas produções com os contextos sociais envolvidos. Fundamentados no campo da sociologia (BOURDIEU, 1983) pudemos refletir sobre os processos que envolvem o desenvolvimento do campo científico.

\section{Análise dos dados}

Dividimos a amostragem dos trabalhos internacionais em dois conjuntos: trabalhos sobre IE especificamente e trabalhos sobre 
interpretação ou ILS. A partir de uma apresentação de cada um dos periódicos selecionados, fizemos uma análise do número de publicações por revista; das décadas/anos de publicação; e dos autores e instituições vinculadas às pesquisas por nós destacadas. Ao final, procedemos um cruzamento identificando sua citação em trabalhos de pesquisa (dissertação e tese) sobre a área da interpretação educacional no Brasil.

\section{American Annals of the Deaf}

A American Annals of the Deaf foi publicada pela primeira vez em 1847, é a mais antiga revista acadêmica em inglês com a temática da surdez e da educação de surdos, coordenada pela Gallaudet University nos Estados Unidos da América, com quatro edições anuais.

São mais de 150 anos de trabalho. Todavia, apenas as edições a partir de 1991 estão digitalizadas e disponíveis no Portal de Periódicos da CAPES. Dentre 676 artigos publicados, encontramos apenas cinco sobre ILS e cinco com foco no IE. Dados disponíveis em: < http://interpretaremlibras.blogspot.com.br/2012/06/american-annals-of-deaf.html

\section{Sign Language Studies}

A Sign Language Studies é coordenada pela Gallaudet University - EUA, começou a ser publicada em 1972. A publicação digitalizada e disponibilização se deu a partir de 2000. Teve como primeiro editor William C. Stokoe, seguido por David Armstrong e desde 2009 o cargo é de Ceil Lucas, Professor de Linguística da Universidade Gallaudet.

Dentre os 161 artigos publicados e disponíveis, identificamos quatro publicações em diversas áreas do ILS e dois relacionados ao trabalho do IE. Dados disponíveis em: < http://interpretaremlibras.blogspot.com.br/2012/06/sign-language-studies.html 


\section{Journal of Deaf Studies and Deaf Education}

A Journal of Deaf Studies and Deaf Education teve início em 1996 e as publicações estão disponíveis desde sua criação, contando com 13 volumes, disponibilizando os textos completos dos artigos. A revista é composta por quatro números anuais. O editor chefe é Marc Marschark e a edição esta a cargo da Oxford University Press - Nova York.

A revista já publicou 366 artigos. Encontramos quatro artigos sobre ILS e treze artigos sobre IE. Dados disponíveis em: < http:// interpretaremlibras.blogspot.com.br/2012/06/desde-1996-journal-of-deaf-studies-and.html >

\section{Sign Language \& Linguistics}

A Sign Language \& Linguistics é publicada desde 1998, geralmente com duas edições anuais. $\mathrm{O}$ foco dela é discutir as línguas de sinais no contexto mais amplo da linguagem natural, se propondo a ser um espaço de conhecimento da gramática com base nos estudos linguísticos, abordando especificamente o efeito da modalidade gestual-visual. Publicada pela John Benjamins Editora, Amsterdan, tem como editores Josep Quer da ICREA \& Universitat Pompeu Fabra e Roland Pfau da University of Amsterdam. O revisor da edição é Gaurav Mathur da Gallaudet University.

Foram 97 artigos publicados nestes 14 anos, dentre estes apenas um sobre ILS. Dados disponíveis em: < http://interpretaremlibras. blogspot.com.br/2012/06/sign-language-linguistics.html > .

\section{Deafness \& Education International}

Revista está disponível desde 1999 e está em seu décimo terceiro volume (2011). Tem 4 volumes anuais sendo ao total 40 números. É produto da parceria entre a British Association of Teachers of the Deaf (BATOD) e da Australian National Association of Teachers of the Deaf (NAATD). 
A editora chefe é Linda Watson (School of Education, University of Birmingham, $U K$ ) da Inglaterra. Tendo também um editor na Austrália, P. Margaret Brown (Melbourne Graduate School of Education, University of Melbourne).

Não há nenhum artigo publicado que tenha como foco o ILS dentre os 140 artigos disponíveis. Dados disponíveis em: < http:// interpretaremlibras.blogspot.com.br/2012/06/deafness-education-international.html >

\section{The Sign language translator and interpreter}

A revista The Sign language translator and interpreter teve início em 2007 e periodicidade de duas publicações anuais, tendo apenas os três primeiros volumes publicados, foi interrompida em 2010. Esta decisão aconteceu pela constatação dos editores de haver poucos especialistas em tradução de língua de sinais vinculados a espaços acadêmicos de pesquisa. Por este motivo não conseguiram manter um fluxo consistente de artigos de qualidade.

Todavia, a editora São Jerônimo continua aceitando artigos sobre intérprete de língua de sinais, em uma série de livros dedicados a este tema denominado de "The Sign Language Translator and Interpreter Series".

O material era publicado na Inglaterra e compilava principalmente produções da Europa. Seus editores foram Lorraine Leeson da Trinity College Dublin (Irlanda) e Review Editor Svenja Wurm, Heriot-Watt University (Escócia).

Ao total foram 24 artigos publicados sobre ILS, e apenas um tratava de alguma forma sobre IE. Dados disponíveis em: < http:// interpretaremlibras.blogspot.com.br/2012/06/sign-language-translator-and.html >

\section{International Journal of Interpreter Education (IJIE)}

International Journal of Interpreter Education é uma revista pioneira abordando temas sobre formação de intérpretes de língua 
de sinais. A editora chefe é Jemina Napier da University Macquarie (Austrália).

A revista foi criada em 2009 e tem um volume anual, no qual todos os artigos são focados no trabalho do ILS, foram publicados 3 artigos em 2009 e 6 artigos em 2010. Dentre esses, uma publicação refere-se ao trabalho IE. Dados disponíveis em: < http://interpretaremlibras.blogspot.com.br/2012/06/international-journal-of-interpreter.html $>$.

\section{Tradução/interpretação de Língua de sinais e Interpretação educacional: campos em construção}

Constatamos que o foco das primeiras revistas era as áreas da linguística e da educação de surdos. Os artigos sobre interpretação apareceram timidamente a partir do ano de 1992 e foram crescendo lentamente em número. A área específica da interpretação em língua de sinais foi contemplada posteriormente com a criação de periódicos com interesse focal (revistas 6 e 7) .

A interpretação educacional foi por muito tempo pouco apreciada pelos próprios intérpretes em comparação à outras áreas de interpretação como a interpretação comunitária/social por exemplo, sem que isso tivesse lastro em qualquer consideração empírica. Talvez se possa argumentar que, em geral, a área da Educação Básica não ofereça alta remuneração e exige que o intérprete atue quase que exclusivamente nesta atividade, já que envolve um bom número de horas semanais. A atuação como intérprete em outras áreas sociais favorece uma atuação mais autônoma, com horas e valores a serem combinados entre as partes envolvidas dando maior liberdade ao profissional.

Atualmente se começa a visualizar que o conhecimento e as habilidades envolvidas em cada domínio da atuação de ILS são específicos, podendo haver, em alguns casos, uma transferência de um campo para o outro. A área da IE se configura como uma 
área específica, pois demanda questões e análises próprias como: formação do intérprete, familiarização com o conteúdo acadêmico da turma onde trabalha, habilidades de interpretação apropriadas para cada tipo de público entre outras (MARSCHARK, SAPERE e SEEWAGEN, 2005).

Pela tabela 1, visualizamos a quantidade de publicação sobre tradução/interpretação de língua de sinais e a de interpretação educacional levantada em nossa amostra.

\begin{tabular}{|l|l|l|l|l|l|}
\hline \multicolumn{5}{|c|}{ Tabela 1 } \\
\hline Por temas & $\begin{array}{l}\text { Publicação } \\
\text { desde }\end{array}$ & $\begin{array}{l}\text { Acervo } \\
\text { disponível } \\
\text { na internet } \\
\text { desde }\end{array}$ & $\begin{array}{l}\text { Total de } \\
\text { artigos } \\
\text { (vários } \\
\text { temas) }\end{array}$ & $\begin{array}{l}\text { Artigos sobre } \\
\text { intérprete } \\
\text { de língua de } \\
\text { sinais (várias } \\
\text { áreas) }\end{array}$ & $\begin{array}{l}\text { Artigos } \\
\text { sobre in- } \\
\text { térprete } \\
\text { educa- } \\
\text { cional }\end{array}$ \\
\hline $\begin{array}{l}\text { 1- American annals } \\
\text { of the deaf }\end{array}$ & 1847 & 1991 & $676^{*}$ & 5 & 5 \\
\hline $\begin{array}{l}\text { 2- Sign Language } \\
\text { Studies }\end{array}$ & 1972 & 2000 & $161^{*}$ & 4 & 1 \\
\hline $\begin{array}{l}\text { 3- Journal of Deaf } \\
\text { Studies and Deaf } \\
\text { Education }\end{array}$ & 1996 & 1996 & 366 & 6 & 12 \\
\hline $\begin{array}{l}\text { 4- Sign Language \& } \\
\text { Linguistics }\end{array}$ & 1998 & 1998 & 97 & 1 & 0 \\
\hline $\begin{array}{l}\text { 5- Deafness } \\
\text { \& Education } \\
\text { International }\end{array}$ & 1999 & 1999 & 140 & 0 & 0 \\
\hline $\begin{array}{l}\text { 6- The Sign language } \\
\text { translator and } \\
\text { interpreter }\end{array}$ & 2007 & 2007 & 26 & 25 & 1 \\
\hline $\begin{array}{l}\text { 7- International } \\
\text { Journal of Interpreter } \\
\text { Education }\end{array}$ & 2009 & 2009 & 9 & 8 & $\mathbf{2 0}$ \\
\hline Total & & & $\mathbf{1 . 4 7 5}$ & $\mathbf{4 9}$ & 1 \\
\hline
\end{tabular}

*Este número de publicação refere-se apenas ao cálculo a partir de sua disponibilização na internet. 
Destas sete revistas científicas, a maioria está vinculada a um programa de pós-graduação em Educação ou Linguística. Seus editores são pesquisadores da área de Educação de surdos ou de descrição linguística de língua de sinais.

A revista mais antiga é de 1879 e a mais recente é de 2009. Os trabalhos foram levantados apenas a partir de 1991, segundo a disponibilidade de acesso junto ao Portal de Periódicos da CAPES.

As sete revistas publicaram no período pesquisado um total de 1.475 artigos, sendo destes 49 sobre ILS na área jurídica, médica, em conferência, formação, entre outras e 20 artigos sobre IE. O número de publicações sobre IE é grande em comparação a cada uma das outras áreas de interpretação de língua de sinais indicando que a atuação como IE se constitui como um campo importante.

A área da interpretação educacional tem se revelado uma área independente e ao mesmo tempo multidisciplinar, pois tem sido produzida em programas de pós-graduação em Educação, Linguística Aplicada, Linguística e Educação Especial. Além disso, independente, pois tem se desenvolvido de forma autônoma em relação a outras áreas de interpretação.

Para Bourdieu (2007/1975) há uma hierarquia social dos objetos de pesquisa que orientam os investimentos intelectuais proporcionando um lucro material e simbólico. "O pesquisador participa sempre da importância e do valor que são comumente atribuídos ao seu objeto (...)" (BOURDIEU, 2007, p. 36). Constatamos que as publicações sobre IE se intensificam no período investigado (a partir dos anos 1990s), podendo ser associada à discussão política mundial de inclusão educacional, entre outros fatores.

Dentre os 20 artigos, especificamente dedicados à comunicação de pesquisas sobre IE, descreveremos sua periodicidade em cada revista, por ano/década de publicação. 
Tabela 2

Levantamento de publicações por década/ano

\begin{tabular}{|c|c|c|c|c|c|c|c|c|c|c|c|}
\hline Por ano & anos & 1991 & 1992 & 1993 & 1994 & 1995 & 1996 & 1997 & 1998 & 1999 & 2000 \\
\hline American annals of the deaf & \multirow{7}{*}{$1990 \mathrm{~s}$} & & 1 & & & & & 1 & & & \\
\hline Sign Language Studies & & & & & & & & & & & \\
\hline $\begin{array}{l}\text { Journal of Deaf Studies and Deaf Educa- } \\
\text { tion }\end{array}$ & & & & & & & & & & 2 & \\
\hline Sign Language \& Linguistics & & & & & & & & & & & \\
\hline Deafness \& Education International & & & & & & & & & & & \\
\hline $\begin{array}{l}\text { The Sign language translator and inter- } \\
\text { preter }\end{array}$ & & & & & & & & & & & \\
\hline $\begin{array}{l}\text { International Journal of Interpreter } \\
\text { Education }\end{array}$ & & & & & & & & & & & \\
\hline & anos & 2001 & 2002 & 2003 & 2004 & 2005 & 2006 & 2007 & 2008 & 2009 & 2010 \\
\hline American annals of the deaf & \multirow{7}{*}{$2000 \mathrm{~s}$} & 2 & & & & 1 & & & & & \\
\hline Sign Language Studies & & & & & 1 & & & & & & \\
\hline $\begin{array}{l}\text { Journal of Deaf Studies and Deaf Educa- } \\
\text { tion }\end{array}$ & & & 2 & & 3 & 1 & 2 & & 2 & & \\
\hline Sign Language \& Linguistics & & & & & & & & & & & \\
\hline Deafness \& Education International & & & & & & & & & & & \\
\hline $\begin{array}{l}\text { The Sign language translator and inter- } \\
\text { preter }\end{array}$ & & & & & & & & 1 & & & \\
\hline $\begin{array}{l}\text { International Journal of Interpreter } \\
\text { Education }\end{array}$ & & & & & & & & & & 1 & \\
\hline
\end{tabular}


A tabela 2 mostra o número de artigos produzidos no decorrer dos anos. A tabela é divida em duas partes, nas quais os números são agrupados nas décadas de 1991 a 2000 e do ano 2001 a 2010. Nela se detalha o número de trabalhos em cada um dos anos dos séculos XX e XXI. Cabe destacar o aumento do número artigos apresentados no decorrer das décadas, culminado inclusive com a criação de um periódico endereçado à publicação específica do tema "ILS".

Nos anos 90 foram 4 trabalhos em duas revistas; já de 2001 a 2010 temos 16 artigos apresentados em 5 diferentes revistas. Constatamos o interesse crescente de pesquisa e divulgação na área de interpretação educacional nesta última década.

Para Bourdieu (2007), "o campo dos objetos de pesquisa possíveis tende sempre a organizar-se de acordo com duas dimensões independentes, isto é, segundo o grau de legitimidade e segundo o grau de prestígio no interior dos limites da definição" (BOURDIEU, 2007, p.36).

No contexto atual de desenvolvimento de políticas educacionais inclusivas em diferentes países se fez essencial o incremento de pesquisas sobre os papeis e práticas dos IEs, em muitos casos um profissional novo no cenário educacional que merece ser conhecido, discutido e em muitos aspectos construído enquanto papel e competência profissional.

\section{Autores/pesquisadores dos artigos - a escrita como poder simbólico}

Os autores mais prevalentes nos artigos destacados foram: Jemina Napier (cinco trabalhos), Michael Stinson (cinco trabalhos), Shirin Antia (três trabalhos), Campbell Mid McDer (três trabalhos), Marc Marschark (três trabalhos), Brenda Schick (três trabalhos). Algumas destas publicações foram feitas em conjunto com outros autores indicando o interesse de pesquisadores pela área. 
Os demais autores encontrados têm apenas uma publicação e, por vezes, esta foi realizada em conjunto com autores já citados. Cabe destacar ainda que autores como Napier, Marschark, Antia e Schick têm livros publicados sobre IE.

Constatamos assim uma repetição de autores, mas não necessariamente de temas. Para a produção científica é comum que se permaneça em um determinado campo do saber e se produza diferentes textos científicos com temas relacionados. Os pesquisadores, de forma geral, sobre a "pressão" por publicação o fazem desta forma. Conforme Bourdieu (1983), os pesquisadores vivem em um lugar de lutas e associações, concorrências e acordos. Lutam por capital social e buscam o reconhecimento entre os pares por meio de credibilidade científica.

A produção de conhecimento também é a produção de saberes sociais de articulação, de filiações políticas e teóricas. No campo científico Bourdieu (1983) assinala que o "objeto de disputa" é a posse exclusiva da autoridade científica. Deste ponto de vista, a capacidade de "produzir ciência", por parte de um determinado indivíduo, está agregada a um determinado poder social. Para Bourdieu, nessa luta o que está em jogo é:

[...] o monopólio da autoridade científica definida, de maneira inseparável, como capacidade técnica e poder social; ou, se quisermos, o monopólio da competência científica, compreendida como capacidade de falar e de agir legitimamente (isto é, de maneira autorizada e com autoridade), que é socialmente outorgada a um agente determinado (BOURDIEU, 1983, p. 122).

Para o autor o número de publicações é simbolizado no campo científico como acúmulo, o chamado "crédito científico". Bourdieu (1983) destaca que os conhecimentos produzidos pelos pesquisadores têm como base sua filiação (teórico-metodológica) e são 
dirigidos também para o reconhecimento entre os pares. Em seu livro "Economia das trocas simbólicas", Bourdieu (2008) atribui às instituições em que se usa a linguagem um poder simbólico, como a igreja e a escola/academia. "O uso da linguagem, ou melhor, tanto a maneira como a matéria do discurso, depende da posição social do locutor que, por sua vez, comanda o acesso que se lhe abre à língua da instituição, à palavra oficial, ortodoxa, legítima.” (BOURDIEU, 2008, p.87).

Desta forma, o pesquisador vinculado a um programa de pós-graduação de uma universidade reconhecida e publicando em um veículo (revista científica) com avaliação aceitável, tem conferido maior valor àquilo que ele tem a dizer.

Assim, é possível afirmar que há uma comunidade de pesquisadores interessados no campo da interpretação educacional, que este campo é debatido e justifica uma produção acadêmica e que, além disso, alguns pesquisadores constituem este campo como seu objeto principal de pesquisa.

Nossos dados indicam ainda que os pesquisadores com maior destaque na área de interpretação educacional provêm de instituições educacionais para surdos ou de programas de pós-graduação ligados à educação.

\section{A economia das trocas científicas ${ }^{1}$}

A questão que nos direciona à investigação neste ponto do estudo é: As pesquisas brasileiras sobre IE fazem uso/citação do conhecimento científico internacional? A intenção é construir um cruzamento entre os artigos levantados dos periódicos internacionais com trabalhos de pesquisas nacionais (dissertações e teses) sobre a área da interpretação educacional, considerando sua citação direta ou indireta e a indicação nas referências bibliográficas de cada trabalho. 
O procedimento metodológico foi verificar nas referências bibliográficas dos trabalhos de mestrado e doutorado levantados por Pereira (2010) se havia indicação de citação dos trabalhos internacionais destacados neste estudo. $\mathrm{O}$ trabalho de Pereira foi assumido como paradigma já que a autora faz um levantamento completo de dissertações e teses produzidas no Brasil usando palavras-chaves mais abrangentes, como: língua de sinais, sinais, Libras, e em uma segunda triagem usando as palavras: intérprete(s) e/ou interpretação ou tradução/tradutor(a). Estas opções foram feitas pela autora devido ao amplo espectro semântico que intérprete/interpretação podem abarcar, com estas palavras considerou que chegaria aos trabalhos sobre ILS no Brasil com boa margem de segurança.

Dentre os trabalhos apontados por Pereira (2010), são dezesseis de mestrado e nove de doutorado. Extraímos desta listagem apenas os que estavam relacionados ao intérprete educacional. Compilamos assim, nove trabalhos de mestrado e dois de doutorado, sendo onze trabalhos no total.

Dos trabalhos levantados de mestrado (LEITE, 2004; FILIETAZ, 2006; MARINHO 2007; VIEIRA, 2007; COSTA, 2008; MARTINS, 2008; MARTINS, 2009; MACHADO, 2009; e TUXI, 2009) e de doutorado (ROSSI, 2005; PEDROSO, 2006). Dados disponíveis em: < http://interpretaremlibras.blogspot.com. br/2012/09/dissertacoes-e-teses-2000-2009.html >

\section{Citações de publicações internacionais e sua indicação nas referências bibliográficas das pesquisas nacionais.}

Apresentamos a seguir o levantamento das referencias internacionais citadas nas dissertações e teses brasileiras sobre IE. 


\begin{tabular}{|c|c|c|}
\hline \multicolumn{3}{|c|}{ Dissertação de mestrado } \\
\hline Autor & $\begin{array}{l}\text { Artigos deste } \\
\text { estudo citados }\end{array}$ & $\begin{array}{l}\text { Outros artigos/textos internacionais } \\
\text { citados }\end{array}$ \\
\hline $\begin{array}{l}\text { LEITE } \\
(2004)\end{array}$ & - & $\begin{array}{l}\text { COKELY, D. Sign language: Teaching, } \\
\text { interpreting, \& educational policy. In } \\
\text { Sign Language \& the Deaf Community: } \\
\text { Essays in Honor of William C. Stokoe. } \\
\text { Ed. Baker \& Battison, 137-158. Silver } \\
\text { Spring, MD: The National Association of } \\
\text { the Deaf, 1980. } \\
\text {. The interpreted medical inter- } \\
\text { view: It loses something in the transla- } \\
\text { tion. The Reflector 3:5-11, 1982. } \\
\text { FRISHBERG, N. Interpreting: An Intro- } \\
\text { tuction. Silver Spring, Md.: Registry of } \\
\text { Interpreters for the Deaf, Inc. Revised } \\
\text { Edition, 1990. } \\
\text { JOHNSON, K. Miscommunication in } \\
\text { Interpreted Classroom Interaction. SLS } \\
\text { 70, Spring. In: Cokely, D. Ed. Sign } \\
\text { Language Interpreter and Interpreting. } \\
\text { SLS Monographs Series Linstok Press, } \\
\text { 1991/1992. } \\
\text { METZGER, M. Sign Language Inter- } \\
\text { preting: desconstructing the myth of } \\
\text { neutrality. Gallaudet University Press. } \\
\text { Washington, D. C, 1999. } \\
\text { ROY, C. B. Interpreting as a Discourse } \\
\text { Process. Oxford Universit Press, New } \\
\text { York, 2000. }\end{array}$ \\
\hline $\begin{array}{l}\text { FILIETAZ } \\
(2006)\end{array}$ & - & $\begin{array}{l}\text { VERNON, M. Early manual comunica- } \\
\text { tion and deaf children's achievement. } \\
\text { American Annals of the Deaf. } 1970 .\end{array}$ \\
\hline $\begin{array}{l}\text { MARINHO } \\
(2007)\end{array}$ & - & $\begin{array}{l}\text { METZGER, M. Sign interpreting } \\
\text { descontructing the myth of neutrality. } \\
\text { Washington: Gallaudet University Press, } \\
1999 .\end{array}$ \\
\hline
\end{tabular}




\begin{tabular}{|c|c|c|}
\hline $\begin{array}{l}\text { VIEIRA } \\
(2007)\end{array}$ & - & $\begin{array}{l}\text { METZGER, M. Sign Language Interpre- } \\
\text { tin: desconstructing the myth of neutral- } \\
\text { ity. } \\
\text { Gallaudet University Press. Washington, } \\
\text { D.C. 1999a. } \\
\text { NAPIER, Jemina. Sign Language Inter- } \\
\text { preting: theory and practice in Australia } \\
\text { and New Zealand. The Federation Press. } \\
\text { Sydney, NSW. 2006. } \\
\text { NAPIER, Jemina. Linguistic coping } \\
\text { strategies of sign language interpreters } \\
\text { in higher education. Página acessada em } \\
\text { Setembro de 2004. http://www.online- } \\
\text { conference.net/sdp1/papers_sdp1.htm } \\
\text { RODRÍGUEZ, Éster de Los Santos. Téc- } \\
\text { nicas de Interpretacion de La Lengua de } \\
\text { Signos. Fundacion CNSE para la supre- } \\
\text { sión de las barreras de la comunicacion. } \\
\text { 2.ed. - 2001. } \\
\text { WINSTON. Elisabeth A. Educational } \\
\text { interpreting: how it can suceed. Washing- } \\
\text { ton: Gallaudet University Press, 2004. }\end{array}$ \\
\hline $\begin{array}{l}\text { COSTA } \\
(2008)\end{array}$ & - & \\
\hline $\begin{array}{l}\text { MARTINS } \\
(2008)\end{array}$ & - & $\begin{array}{l}\text { METZGER, M. Sign Language In- } \\
\text { terpreting: deconstructing the myth of } \\
\text { neutrality. } 2 \text { ed.Washington: Gallaudet } \\
\text { University Press, } 2000 \text {. } \\
\text { ROY, C. B. Interpreting as a discourse } \\
\text { process. Oxford University Press, } 1999 \text {. } \\
\text {. Innovative practices for teaching } \\
\text { sing language interpreters. Washington, } \\
\text { Gallaudet University Press, 2000. } \\
\text { STEWART, D.; SCHEIN, J.; CART- } \\
\text { WRIGHT, B. Sign Language Interpret- } \\
\text { ing: exploring its art and science. Allyn } \\
\text { and Bacon, 1998. }\end{array}$ \\
\hline $\begin{array}{l}\text { MARTINS } \\
\text { (2009) }\end{array}$ & - & \\
\hline
\end{tabular}




\begin{tabular}{|c|c|c|}
\hline $\begin{array}{l}\text { MACHADO } \\
\text { (2009) }\end{array}$ & - & $\begin{array}{l}\text { PLAZAS, M. M. R. Servicios de } \\
\text { interpretación para personas Sordas } \\
\text { y sordociegas. El bilinguismo de los } \\
\text { sordos, Santa Fé de Bogotá, v. 1, n. 14, } \\
\text { mar. } 2000 .\end{array}$ \\
\hline $\begin{array}{l}\text { TUXI } \\
\text { (2009) }\end{array}$ & $\begin{array}{l}\text { SHAW, J e } \\
\text { JAMIESON, } \\
\text { J. Patterns } \\
\text { of classroom } \\
\text { discourse in } \\
\text { integrated, } \\
\text { interpreted } \\
\text { elementary } \\
\text { school setting. } \\
\text { American } \\
\text { Annals of the } \\
\text { Deaf. V 142, } \\
\text { n.1. } 1997 . \text { P. } \\
40-47\end{array}$ & $\begin{array}{l}\text { FRISHBERG, N. Interpreting: An Intro- } \\
\text { tuction. Silver Spring, Md.: Registry of } \\
\text { Interpreters for the Deaf, Inc. Revised } \\
\text { Edition, 1990. } \\
\text { COKELY, D. Sign language. Teach- } \\
\text { ing, interpreting, \& educational policy. } \\
\text { In Sign language \& the Deaf Comunity: } \\
\text { Essays in Honor of William C. Stokoe. } \\
\text { Ed. Baker \& Batison, 137-158. Silver } \\
\text { Spring. MD: The National Association of } \\
\text { the Deaf, 1980. } \\
\text { LUCKNER, J. L.; MUIR, S. Successful } \\
\text { student who are deaf in general educa- } \\
\text { tional settings. American Annals of the } \\
\text { deaf, 146 (5). P.435-445, 2001. } \\
\text { KLUWIN, T.M. Coteaching Deaf and } \\
\text { Hearing students: Research on social In- } \\
\text { tegration. American Annals of the Deaf, } \\
\text { 144(4), 339-344, 1999. } \\
\text { NAPIER, Jemina. Sign language Inter- } \\
\text { preter Traineing, Testing, and Acredit- } \\
\text { tarion: An International comparison. } \\
\text { American Annals of the deaf, 149 (4). } \\
\text { 2004. } \\
\text { PLAZA, M. M.R. Servicios de interpre- } \\
\text { tación para personas sordas y sordocie- } \\
\text { gas. El bilinguismo de los sordos, Santa } \\
\text { Fé de Bogotá, v.1, n.14, março } 2000 .\end{array}$ \\
\hline
\end{tabular}




\begin{tabular}{|l|l|l|}
\hline \multicolumn{3}{|c|}{ Tese de doutorado } \\
\hline Autor & $\begin{array}{l}\text { Artigos deste } \\
\text { estudo citados }\end{array}$ & $\begin{array}{l}\text { Outros artigos/textos internacionais } \\
\text { citados }\end{array}$ \\
\hline $\begin{array}{l}\text { ROSSI } \\
(2005)\end{array}$ & - & $\begin{array}{l}\text { ROBERTS, E. Signs language interpret- } \\
\text { ing services in China. In: CALLAWAY, } \\
\text { A. Deafness and development: learning } \\
\text { from projects with deaf children and deaf } \\
\text { adults in developing countries. England: } \\
\text { University of Bristol Print Services, } \\
\text { 2001. }\end{array}$ \\
\hline $\begin{array}{l}\text { PEDROSO } \\
(2006)\end{array}$ & $\begin{array}{l}\text { ANTIA, S.D.; } \\
\text { KREIMEYER, } \\
\text { K.H. The role } \\
\text { of interpreter in } \\
\text { inclusive class- } \\
\text { rooms. Ameri- } \\
\text { can Annals of } \\
\text { the Deaf, 146 } \\
\text { (4), p. 355-365, } \\
\text { 2001 }\end{array}$ & $\begin{array}{l}\text { FAMULARO, R. Intervención del inté- } \\
\text { rprete de lengua de señas/lengua oral em } \\
\text { Int SKIAR, C. (org.) Atualidade da } \\
\text { educação bilíngüe para surdos. Vol. 1. } \\
\text { Porto Alegre: Editora Mediação, 1999. }\end{array}$ \\
\hline
\end{tabular}

Constatamos que das 49 possibilidades de leitura e referenciação presentes nos sete periódicos internacionais pesquisados, apenas duas foram citadas: ANTIA e KREIMEYER (2001) e SHAW e JAMIESON (1997). Dos onze trabalhos brasileiros apenas o de Pedroso (2006) e Tuxi (2009) fizeram uma citação cada, de artigo do periódico American Annals of the Deaf que corresponde a 2 dentre os 49 artigos do nosso levantamento inicial.

Tuxi (2009) cita outros quatro artigos da mesma revista, American Annals of the Deaf, mas que não tratam especificamente sobre intérprete educacional. Destaca-se que nesta dissertação não aparece no título, resumo ou nas palavras de busca os termos intérprete de língua de sinais ou intérprete educacional, apesar do estudo trabalhar com aspectos de inclusão de surdos e codocência. No Brasil, atualmente, a experiência de alguém atuar em espaços de educação 
inclusiva vertendo da língua portuguesa para Libras e vice-versa tem sido nomeada de diferentes modos: intérprete de libras, intérprete educacional, professor-intérprete, professor-interlocutor, bidocência, codocência entre outros, o que muitas vezes dificulta a identificação de fazeres semelhantes, porém, com vínculos institucionais e nomes diversos (LACERDA, 2009). Dos quatro artigos internacionais citados por Tuxi (2009), um deles fazia parte do nosso levantamento, visto que trata da atuação do intérprete na educação básica.

Leite (2005) cita 4 livros e 2 artigos em inglês; Filietaz (2006) cita 1 artigo em inglês; Marinho (2007) cita 1 livro em inglês; Vieira (2007) cita 3 livros e 1 trabalho em anais de conferência em inglês e 1 livro em espanhol. Já, Costa (2008) e Martins (2009) não fazem nenhuma citação internacional sobre ILS ou IE; Martins (2008) cita 4 livros em inglês. Machado (2009) cita um livro em espanhol. Tuxi (2009) cita 1 livro e 5 artigos em inglês, como também 1 artigo em espanhol. Rossi (2010) cita 1 livro em inglês, e em suas referências apresenta 12 referências internacionais, livros e outros artigos que não das revistas pesquisadas, mas que tratavam da temática geral de educação de surdos. Por sua vez, Pedroso (2006) cita 1 artigo em inglês e 1 artigo em espanhol.

Em primeiro lugar podemos constatar que, de maneira geral, as citações de referência bibliográfica estrangeira são pequenas quando comparadas às citações de autores nacionais dentro de cada dissertação ou tese. Além disso, a maior parte das citações é de livros, ou capítulos de livros, e alguns poucos trabalhos apresentados em anais de eventos ou revistas científicas (periódicos). O número de artigos é bem pequeno e dentre eles ainda mais reduzido aqueles que tratam da questão do IE. A referência de livros internacionais, um pouco mais presente nas dissertações e teses analisadas, parece indicar um hábito mais presente de leitura/consulta a livros que a busca em artigos publicados em periódicos. Destacamos apenas que a maior parte dos livros foi publicada há uma década ou mais, o que pode interferir na atuali- 
dade dos argumentos compartilhados, em um campo de pesquisa muito novo e em constante transformação.

Além disso, consideramos que as questões linguísticas têm um papel importante, já que sabemos que o domínio parcial do idioma inglês por muitos pesquisadores brasileiros nem sempre facilita a consulta e as interações com textos produzidos nesta língua (RODRIGUES e REZENDE, 2010).

Outro fator a ser destacado é a questão do acesso ao Portal CAPES, que seria um facilitador do acesso às bases de textos produzidos fora do Brasil. Este acesso até bem pouco tempo era disponibilizado apenas para as instituições que contavam com Programas de Pós-Graduação com conceito superior a cinco pela CAPES, o que restringia o uso do Portal. Além disso, o acesso era, em geral, feito apenas a partir das instituições e não acessível do computador do usuário final restringindo ainda mais as possibilidades de contato com a literatura estrangeira e consulta.

Ainda, outro ponto que gostaríamos de dar destaque é o lugar da pesquisa com IE em nosso país. Como se trata de um campo recente, não é incomum o depoimento de que a realidade brasileira é singular, de que estamos vivendo algo único em nosso país entre outras percepções equivocadas sobre o que ocorre no contexto da Educação de Surdos em todo o mundo. A leitura cuidadosa dos artigos levantados, na primeira parte desta pesquisa, indica, muitas vezes, que os problemas de formação, conhecimento do conteúdo a ser versado em língua de sinais, aceitação pelos demais profissionais da área da educação, entre outros, não são específicos do Brasil e se repetem em diversos contextos.

Assim, defendemos que uma maior troca entre pesquisadores da área da interpretação educacional seria bem vinda e enriqueceria a todos, pois tanto aqui como fora há percepções e alternativas que poderiam colaborar para a melhoria da Educação de Surdos em diferentes situações. 


\section{Considerações finais}

Pôde-se estabelecer com o levantamento dos periódicos internacionais o seguinte paralelo: a situação da comunicação científica periódica internacional sobre IE tendeu a se adequar aos padrões formais científicos, desenvolvendo periódicos específicos e a consolidar-se como área do conhecimento. Ao mesmo tempo, essa adequação formal, pelos vínculos a programas de pós-graduação e pela presença de editores pesquisadores da área, também contribuiu diretamente para a consolidação destes mesmos periódicos científicos.

A situação atual da produção científica no Brasil sobre o IE tem aumentado e se inscrito em diferentes programas de pós-graduação. Consideramos que, tomando como base o percurso internacional, há indícios de que esse campo também aqui se torne uma área do conhecimento consistente. A revisão de literatura ou estado da arte dentro do campo científico para produção de pesquisas é um procedimento importante para qualquer pesquisador. Nosso levantamento revelou que a interlocução com produções internacionais nesta área ainda é pequena, indicando a pouca articulação e debate com a produção científica não local, ou seja, não é possível afirmar que tais estudos estejam influenciando, ao menos de maneira direta, as pesquisas e conhecimento acumulado em nosso país. Mas, entendemos que as reflexões aqui apresentadas podem instigar uma busca mais ativa no cenário nacional por estudos e pesquisas no exterior no campo da interpretação educacional, ampliando as redes de pesquisa e favorecendo um adensamento mais acelerado do conhecimento neste campo de estudo. 


\section{Notas}

1. Fazendo alusão ao nome do livro de Bourdieu "economia das trocas simbólicas" e "economia das trocas linguísticas" propomos este subtítulo.

\section{Referências}

ALBRES, N.A. Tradução e interpretação em língua de sinais como objeto de estudo: produção acadêmica brasileira: 1980 a 2006. Campo Grande: EPILMS 17 e 18 de novembro, 2006.

BARROS, D.L.P.de. Dialogismo, polifonia e enunciação. Dialogismo, polifonia e enunciação. In: e FIORIN, J.L. Dialogismo, polifonia, intertextualidade: em torno de Bakhtin Mikhail. São Paulo: USP, 1994. p.1-10.

BRASIL. Decreto-lei n. 5.626, de 22 de dezembro de 2005. Regulamenta a Lei n. 10.436 , de 24 de abril de 2002, que dispõe sobrea Libras.

BEUREN, I.M. e SOUZA, J.C.de. Em busca de um delineamento de proposta para classificação dos periódicos internacionais de contabilidade para o Qualis CAPES. Rev. contab. finanç. 2008, vol.19, n.46, p. 44-58.

BOURDIEU, P. O campo científico. In: ORTIZ, R. (Org.). Pierre Bourdieu: sociologia. São Paulo: Ática, 1983, p. 122-155.

. Método científico e hierarquia social dos objetos. In: NOGUEIRA, M.A.; CATANI, A. Escritos de Educação. Petrópolis, RJ: Vozes, 2007. p.33-38.

. A Economia das trocas linguísticas. São Paulo: Edusp, 2008. 
204 Neiva de A. Albres \& Cristina B. Feitosa de Lacerda, Interpretação...

BRASIL. Ministério da Educação. Diretrizes nacionais para a educação especial na educação básica. MEC/SEESP, 2001.

Política nacional de educação especial na perspectiva da educação inclusiva. Janeiro de 2008.

LACERDA, C.B.F. Intérprete de LIBRAS: em atuação na educação infantil e no ensino fundamental. 1. ed. Porto Alegre: Editora Mediação/FAPESP, 2009.

MARSCHARK, M., SAPERE, P., \& SEEWAGEN, R. Preface. In: MARSCHARK, M.; PETERSON, R.; \& WINSTON, E.A. (Eds.), Sign language interpreting and interpreter education: Direction for research and practice. New York: Oxford University Press. 2005.

McCLEARY, L.E. Prefácio. In: WILCOX, S.; WILCOX, P.P. Aprender a ver: $\mathrm{O}$ ensino da língua de sinais americana como segunda língua. Rio de Janeiro: Arara Azul, 2005.

PEREIRA, M.C.P. Produções acadêmicas sobre interpretação de língua de sinais: dissertações e teses como vestígios históricos. Cadernos de Tradução, volume 1, No 26. Florianópolis: UFSC, 2010.

RODRIGUES, L.O.C. e REZENDE, N.A.de. O tamanduá olímpico a caminho da obesidade científica. Rev Med Minas Gerais 2010; 20(3): p.375-379.

SANTOS, E.T. Tracejando a "andança investigativa": o que trago no alforge para compreender a aprendizagem do professor e do adulto no campo das tecnologias digitais? In: FREITAS, M.T.A. e RAMOS, B.S. (orgs.). Fazer pesquisa na abordagem histórico-cultural: metodologias em construção. Juiz de Fora: UFJF, 2010.

VANTI, N.A.P. Da bibliometria à webometria: uma exploração conceitual dos mecanismos utilizados para medir o registro da informação e a difusão do conhecimento. Ci. Inf. 2002, vol. 31, n. 2, p.369-379.

Recebido em 16/10/2012

Aceito em 05/01/2013 